Research Article

\title{
Experimental Investigation on the Flow Resistance of a Staged Fuel Injector with Thermal Protection
}

\author{
Jingyu Zhang $\mathbb{D}^{\mathbb{D}}$, Xinyi Wang $\left(\mathbb{D}, \mathrm{Yu}_{\mathrm{Wu}} \mathrm{W}\right.$, and Xiaomin $\mathrm{He}$ \\ College of Energy and Power Engineering, Nanjing University of Aeronautics and Astronautics, Nanjing, Jiangsu 210016, China \\ Correspondence should be addressed to Xinyi Wang; wxy_lila@nuaa.edu.cn
}

Received 28 September 2020; Revised 19 February 2021; Accepted 6 March 2021; Published 31 March 2021

Academic Editor: Jun-Wei Li

Copyright (C) 2021 Jingyu Zhang et al. This is an open access article distributed under the Creative Commons Attribution License, which permits unrestricted use, distribution, and reproduction in any medium, provided the original work is properly cited.

\begin{abstract}
The multistaged rotating swirling usually adopts the staged combustion and multiple point fuel supply, which has the advantages of high efficiency and low emissions. However, the high inlet temperature rise will cause autooxidation and fuel coking. Multiple fuel circuit mutual cooling technology by using different flight conditions is an effective measure for the thermal protection of the nozzle. But the complicated fuel circuit configuration inevitably increase the flow resistance in the fuel jet. This paper presents an experimental investigation of flow resistance of a triple-stage rotating swirling nozzle, concerning the effects of various factors on total pressure loss and friction factor in nozzle fuel circuit. The factors include fuel velocity $V_{f, i}$, inlet temperature $T_{f, i}$ , and inlet Reynolds number $\mathrm{Re}_{f, i}$. The results show that the complicated fuel-cooled structure made flow resistance of the pilot fuel circuit much bigger than the main one. Meanwhile, the empirical correlations between the friction factor and the inlet Reynolds number have been fitted, which can be the reference for engineering design.
\end{abstract}

\section{Introduction}

As more performance requirements of aeroengine has been raised, the thrust-to-weight $(T / W)$ ratio of advanced aeroturbine engine tends to be higher. To further improve the $T / W$ ratio of engine, the possible way is to improve the pressure ratio of compressor and the temperature rise of combustor. The increasing of pressure ratio of compressor will increase the inlet temperature of combustor, which could make the fuel autoxidation and deposit formation inside the fuel nozzle. The fuel autoxidation and deposit formation could reduce the life of fuel nozzle [1], significantly. For example, the combustor inlet temperature has to be increased to $1000 \mathrm{~K}$ in the advanced high $T / W$ ratio (16 20) engine [2], while the JP-8 fuel was found to start autoxidize and format deposit from $423 \mathrm{~K}$ [3]. The increase of wall temperature of T700 engine fuel nozzle from $450 \mathrm{~K}$ to $480 \mathrm{~K}$ will reduce sharply the nozzle life from 1000 hours to 20 hours [4]. In order to avoid the depositions of coking, decreasing of fuel circuit surface and increasing of the flow resistance, which made strong influence on the flow characteristics, thermal protection is indispensable to ensure the operation in the fuel nozzles.

High efficiency and low emission are two major requirements in the combustor development for advanced aeroengines. Staged combustion is one of the technologies to achieve high efficiency and low emission [5]. In the staged combustion, two stage flames are usually formed inside the combustor: pilot flame and main flame. The pilot flame introduces a small quantity of fuel to stabilize the whole combustion zone; the main flame is stabilized by the pilot flame and carries the most of the combustion and heat-release of the combustor. Staged combustor can be classified as radially staged combustion and axially staged combustion, in which the combustor structure and combustion organization are different. GE Aviation has developed the Twin Annular Premixing Swirler (TAPS) combustor, which is a representative of axially staged combustion (Figure 1). Multiple Point Fuel Injection is adopted to achieve low emission combustion. TAPS produces two coannular swirling flows for the pilot flame and main flame, respectively. Figure 2 presents the fuel nozzle structure of TAPS. A pressure atomizer injector is 


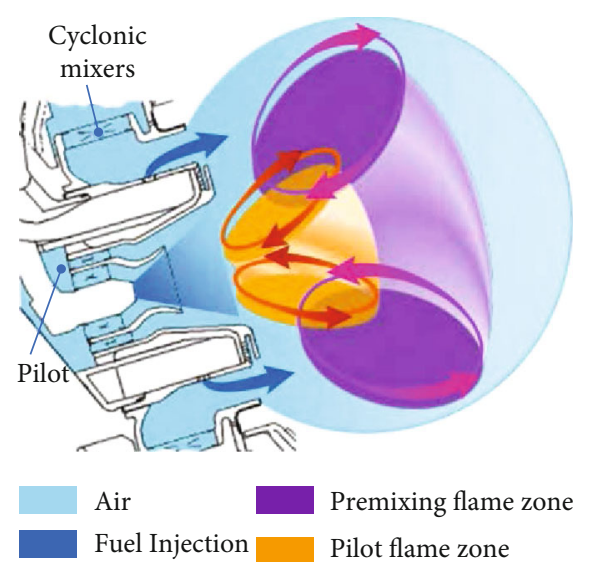

FIgure 1: Combustion organization in TAPS $[7,8]$.

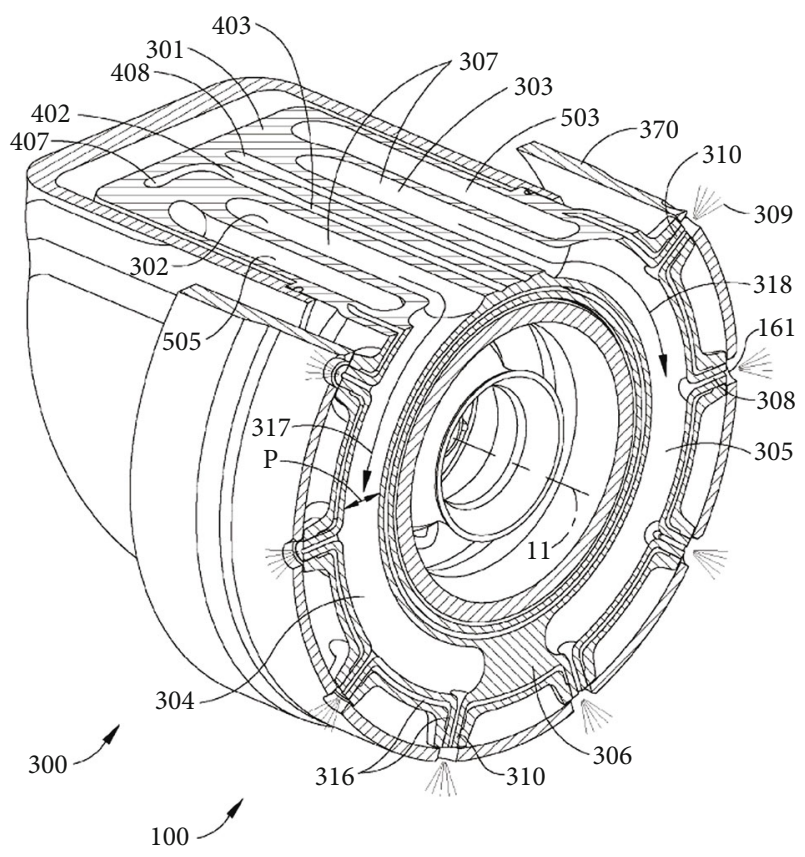

Figure 2: Fuel nozzle structure in TAPS.

installed at the center of the swirling cup for the pilot flame stage. The fuel injector for the main flame stage consists of a cyclone and a cavity with fuel injected by discrete transverse jets. The pilot swirling jet (s) interacts with the main swirling jet (s) separated suitably by a step height to provide thermal environment required to meet combustor's critical design requirements [6].

Nowadays, there are many typical thermal protection methods, for example, increasing the velocity of fuel in lowspeed zone [9], adopting oil cooling structure [7], designing the air gaps [10,11], and using fuel addictive [12]. But every method has their own disadvantages, only one kind thermal protection measure cannot satisfy the requirement. Though the TAPS injector could get better combustion performance than the traditional fuel nozzles, it is difficult to implement the traditional thermal protection method due to the complicated structure. The TAPS uses "cold" fuel passage to cool the

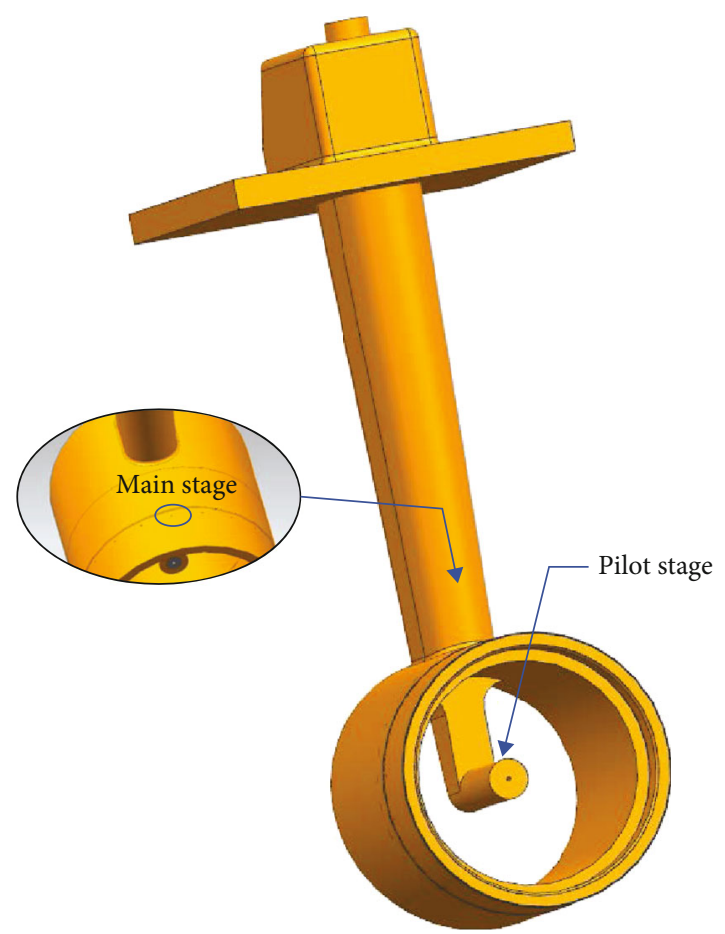

Figure 3: Test injector model.

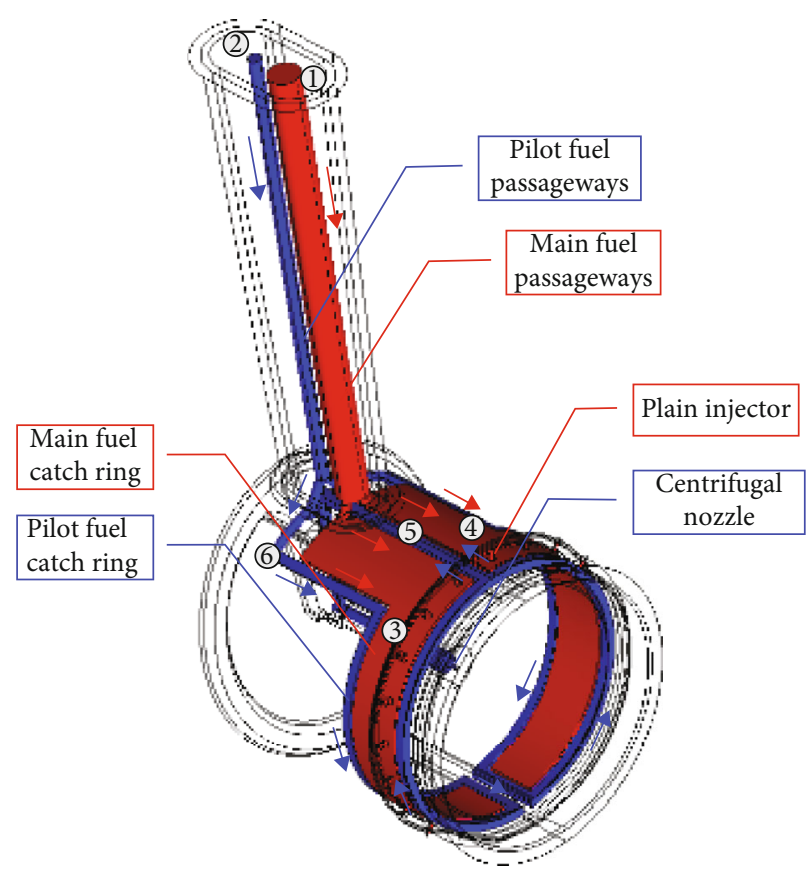

FIgUre 4: Fuel paths model.

"hot" fuel passage $[7,13,14]$. By using the heat sink of fuel, this method can provide good thermal protection performance, especially in the low flow condition [15]. However, the fuel cooling structure has multicircuit and will bring many problems, such as fuel velocity increased, flow path complicated, and flow direction changed, which will increase the flow resistance [16]. Now, there are not many published literatures focused on the flow resistance characteristics. Therefore, the experimental investigation on flow resistance 


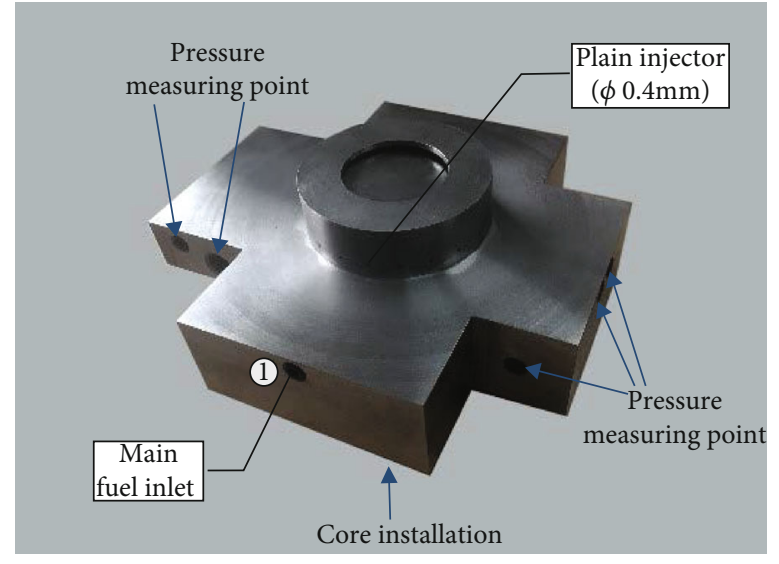

(a) Injector shell

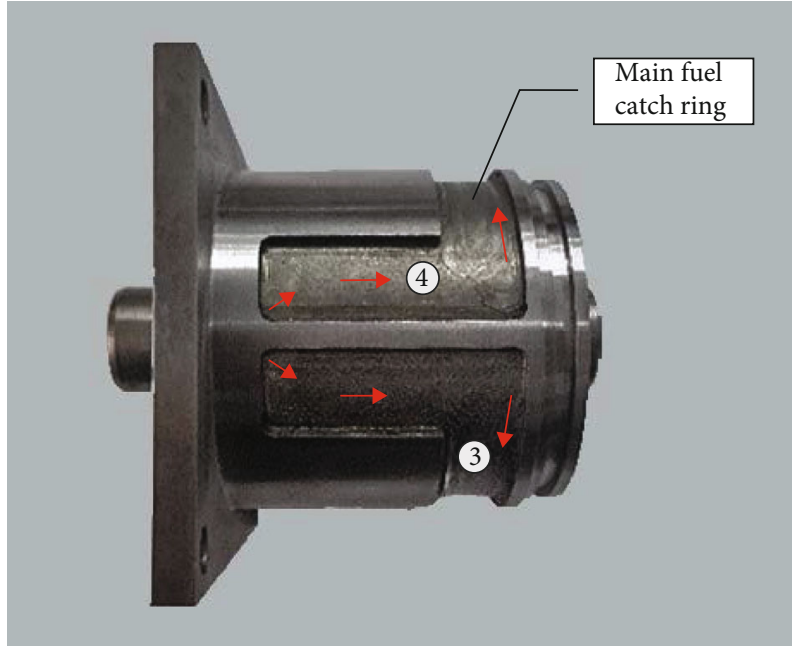

(b) Cylinder core

Figure 5: Test piece of main fuel path.

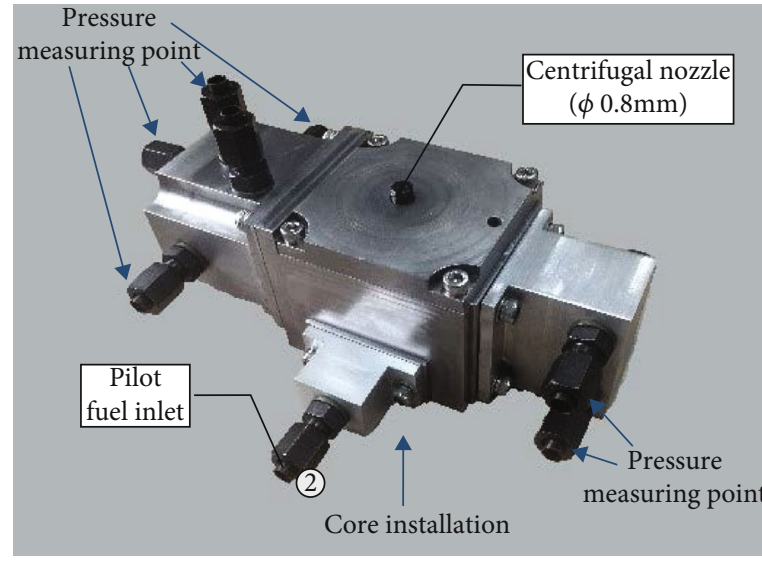

(a) Injector shell

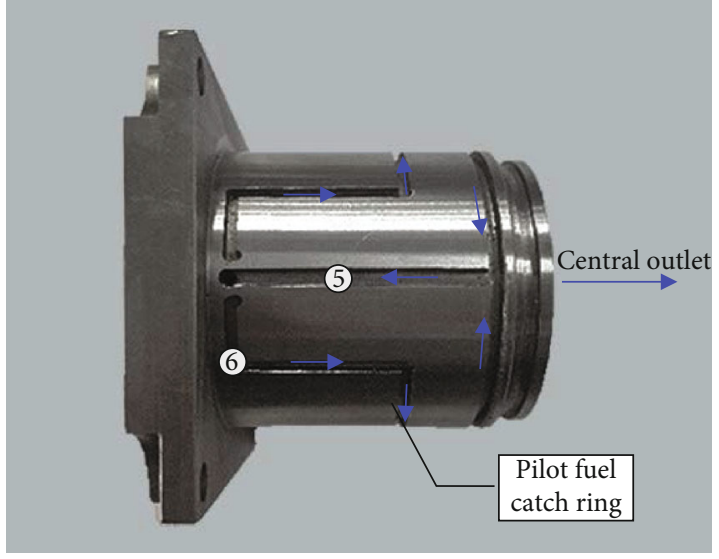

(b) Cylinder core

Figure 6: Test piece of main fuel path.

of typical fuel nozzle mutual cooling structure in a triplestage rotating swirling combustor is developed, and the flow resistance characteristic of complicated fuel cooling structure is analyzed in this paper to provide technical reference and support for advanced fuel supply system design and fuel jet thermal protect structure design in the low emission combustor.

\section{Physical Model}

2.1. Test Model. As shown in Figure 3, the test injector contains two-stage axis swirling jet in the pilot and one-stage radial swirling jet in the main mixer. After flowing along the fuel passageways, both main fuel and pilot fuel are divided into two paths and flow into the catch ring. Twenty plain orifice injectors extend radially along the main swirling jet. The pilot circuit is surrounded along the annular main fuel circuit, than come together in front of the nozzle. The pilot path adopts a centrifugal nozzle located at the annular center (Figure 4).
TABle 1: Test case.

\begin{tabular}{lcc}
\hline Fuel circuit & Inlet temperature $(\mathrm{K})$ & Inlet velocity $(\mathrm{m} / \mathrm{s})$ \\
\hline Main fuel circuit & $303-348$ & $1.0 \sim 3.9$ \\
Pilot fuel circuit & $303-373$ & $0.5 \sim 3.6$ \\
\hline
\end{tabular}

The test sections of both main and pilot fuel path are processed separately. The test piece of main fuel path includes a fuel inlet pipe, a cylinder core, and shell. The fuel paths are formed by interference fit of the shell and the core to ensure well sealing (Figure 5). The fuel enters the path from the inlet pipe (1) in Figure 4). The cylinder core is slotted as the fuel catch ring path (3) and (4) in Figure 4). The holes around the cylinder torus above the housing are corresponded the 20 plain injectors in Figure 4.

The design of pilot test section is similar with the main one, the fuel paths are formed by slotting method (Figure 6 (5), (6)). (2) is the fuel inlet, and the outlet of centrifugal nozzle 


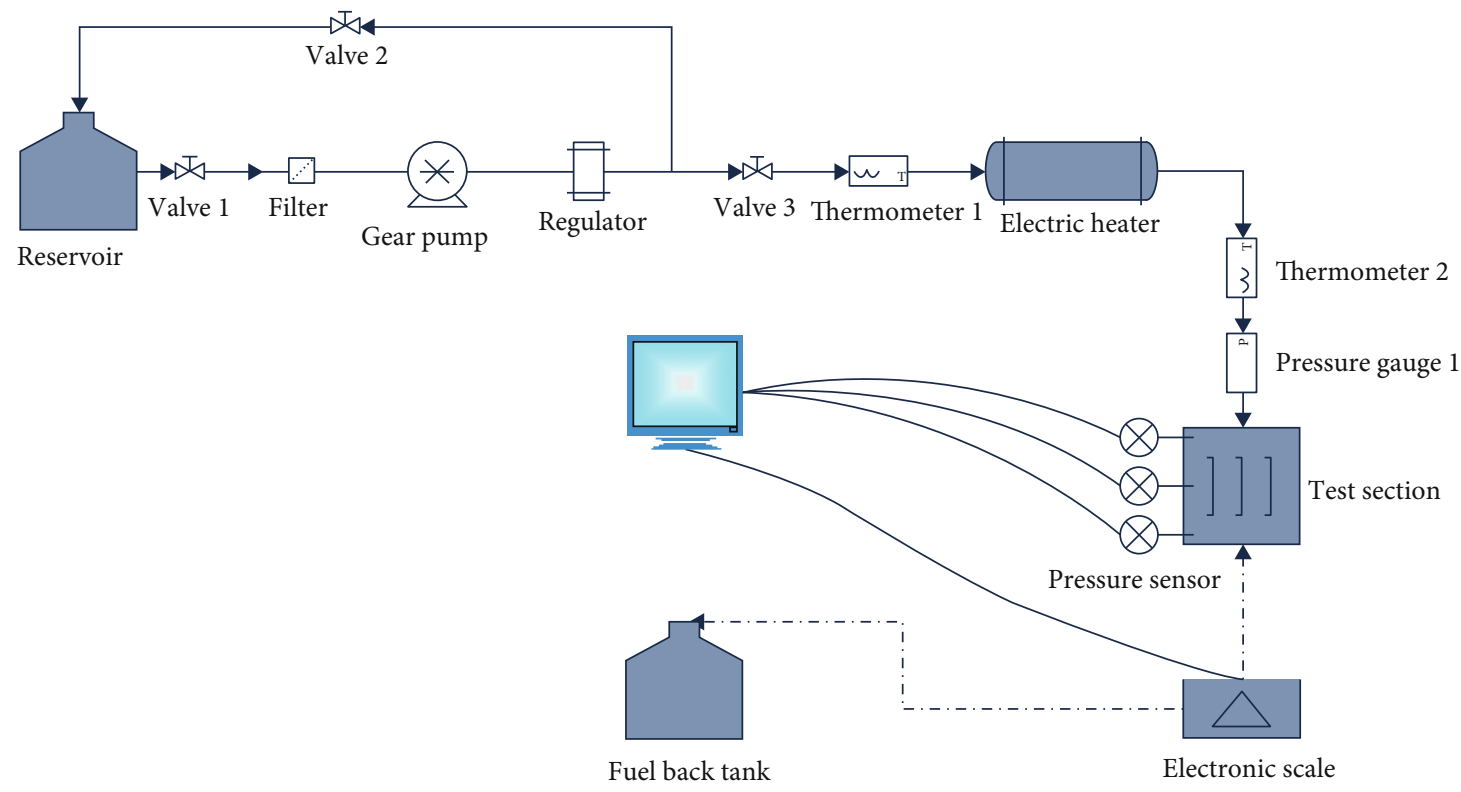

Figure 7: Test injector model.

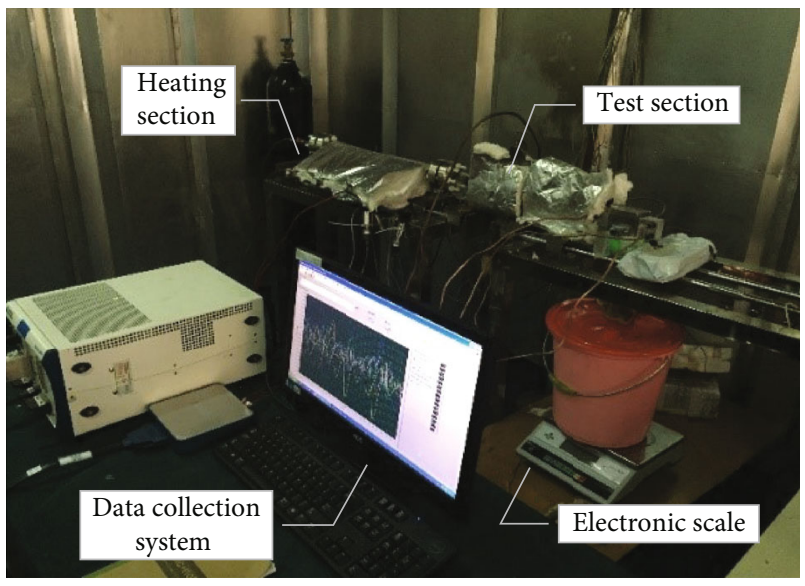

Figure 8: Experimental system.

is above the housing. The numbers of fuel path in Figures 5 and 6 correspond to the numbers in Figure 4.

2.2. Test Case. The China RP-3 fuel is adopted in the present study. The density and viscosity of RP-3 fuel are affected by temperature slightly. Formulas of fuel density and viscosity coefficient with temperature have been fitted in this paper:

$$
\begin{gathered}
\rho=942.85715-0.37557 T-6.38744 \times 10^{-4} T^{2}, \\
\mu=0.0246-2.0210 \times 10^{-4} T+6.3619 \times 10^{-7} T^{2}-8.9865 \\
\times 10^{-10} T^{3}+4.7747 \times 10^{-13} T^{4} .
\end{gathered}
$$

The outlet pressure of experimental system is ambient pressure, the operation conditions is listed in Table 1, and
TABLE 2: Accuracy and range of pressure measuring equipment.

\begin{tabular}{lcc}
\hline & Range $(\mathrm{MPa})$ & Accuracy \\
\hline Pressure sensor & $0 \sim 3$ & $0.3 \%$ \\
& $0 \sim 6$ & $0.3 \%$ \\
Pressure difference sensor & $0 \sim 0.25$ & $0.3 \%$ \\
Precise pressure gauge & $0 \sim 0.5$ & $0.3 \%$ \\
& $0 \sim 6$ & $0.4 \%$ \\
\hline
\end{tabular}

the range of inlet velocity has covered all the typical flight conditions.

\section{Experimental Method}

3.1. Experimental System. As shown in Figures 7 and 8, the experimental system includes the fuFel supply system, heating system, test section, and measurement system. The gear pump can supply maximum $14.7 \mathrm{MPa}$ fuel pressure, fuel passes the filter $(10 \mu \mathrm{m})$ and the regulator, and the valve is used to adjust the flow rate. In the heating system, the power can be controlled by the differences between thermometers 1 and 2. For the pilot fuel circuit where the flow rate is smaller, the SCR (Silicon controlled rectifier) heating system is adopted, of which the voltage and current range are $0 \sim 30 \mathrm{~V}$ and $0 \sim 300 \mathrm{~A}$, respectively. For the main fuel circuit where the flow rate is higher, the oil-bath heater whose working temperature can be adjusted from $20^{\circ} \mathrm{C}$ to $300^{\circ} \mathrm{C}$ is adopted. The heating section is insulated by aluminosilicate fiber cladding whose thermal conductivity is lower than $0.17 \mathrm{~W} /(\mathrm{m} \cdot \mathrm{K})$. After being heated, the fuel enters in the test section, the electronic scale can record the increment of the mass flow in the unit time to get the fuel velocity where the collection frequency is almost $2 \mathrm{~Hz}$. 


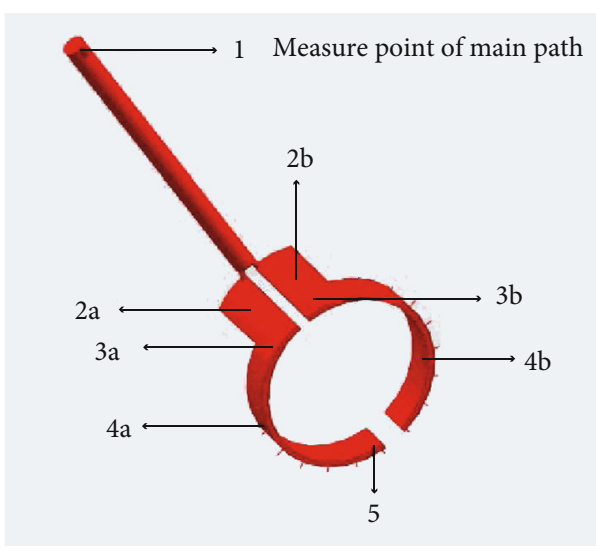

(a) Main fuel path

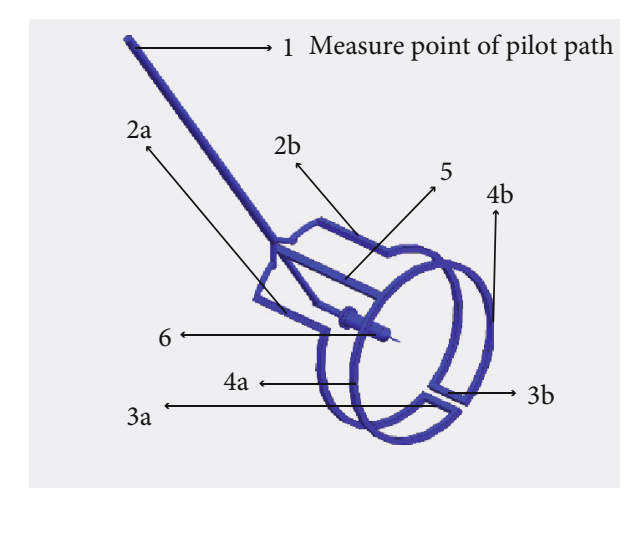

(b) Pilot fuel path

FIGURE 9: Schematic diagram of the measure point.

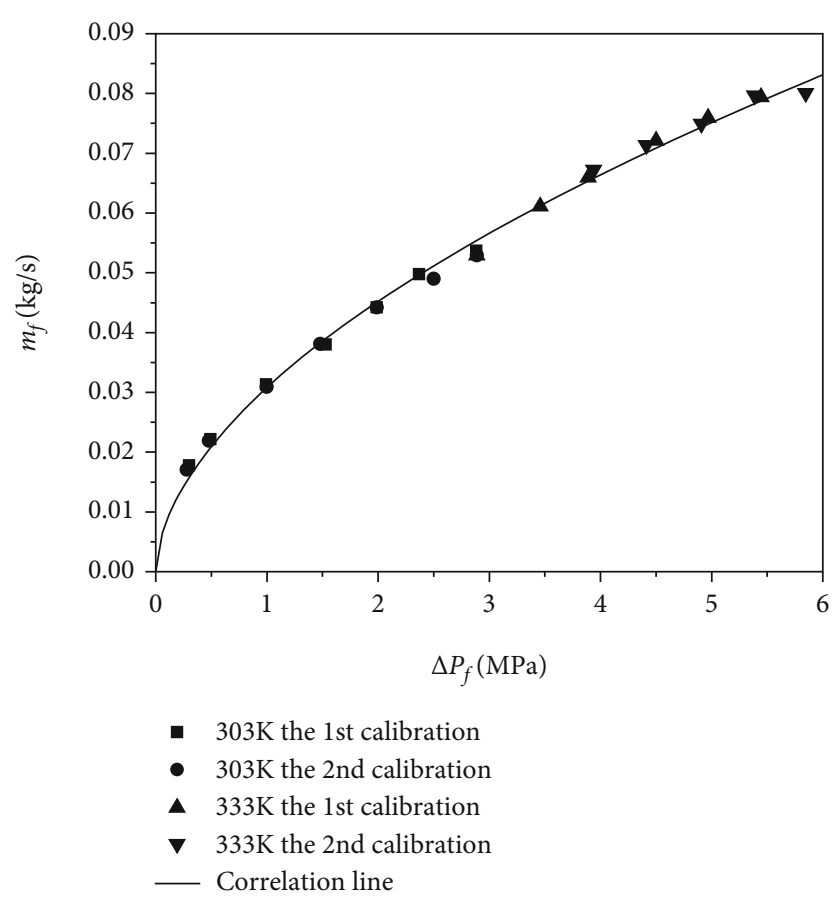

(a) Main fuel circuit

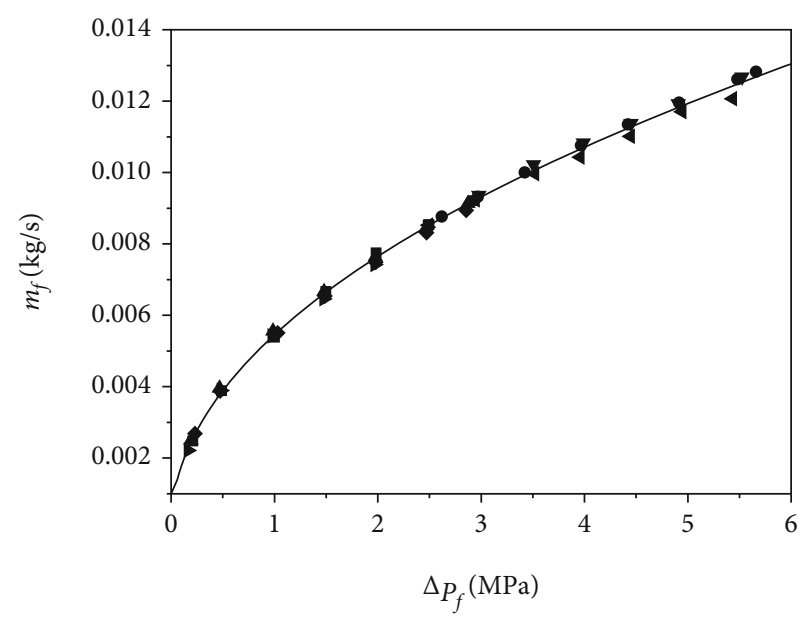

- The $1^{\text {st }}$ calibration at ambient temperature

- The $2^{\text {nd }}$ calibration at ambient temperature

- The $3^{\text {rd }}$ calibration at ambient temperature

v The $4^{\text {th }}$ calibration at ambient temperature

- $333 \mathrm{~K}$ the $1^{\text {st }}$ calibration

$4333 \mathrm{~K}$ the $2^{\text {nd }}$ calibration

- $333 \mathrm{~K}$ the $3^{\text {rd }}$ calibration

Correlation line

(b) Pilot fuel circuit

Figure 10: Flux calibration.

\subsection{Measurement System}

3.2.1. Measure Point Position in Experimental System. As shown in Figure 7 , the precise pressure gauge is located upstream of the test section, the pressure sensors and pressure difference sensors are arranged along the test section, and the accuracy and the working range of pressure measuring equipment is shown in Table 2. K-type thermocouples is adopted for getting the temperature of test system; the accuracy of the electronic scale is $0.1 \mathrm{~g}$.

3.2.2. Measure Point Position in Test Section. In the test section, the main fuel circuit has 8 measure points along the path, which is located at the nozzle inlet and both sides of the annular fuel path, respectively. The pilot circuit has 9 measure points, which is located at the path inlet, both sides of the ring, and the fuel convergence section (Figure 9). The pressure in points 2,3 , and 4 is the average value of both symmetric side $\left(P_{2}=\left(P_{2 \mathrm{a}}+P_{2 \mathrm{~b}}\right) / 2\right)$. Pressure sensors are located at every point of main and pilot fuel circuit, and pressure difference sensors are located between different points.

3.2.3. Flux Calibration. There is a functional relationship between the pressure differences of fuel supplying and mass flux, which can be used to calibrate the fuel mass flow rate during the experiment. The experiment has 4 calibrations 


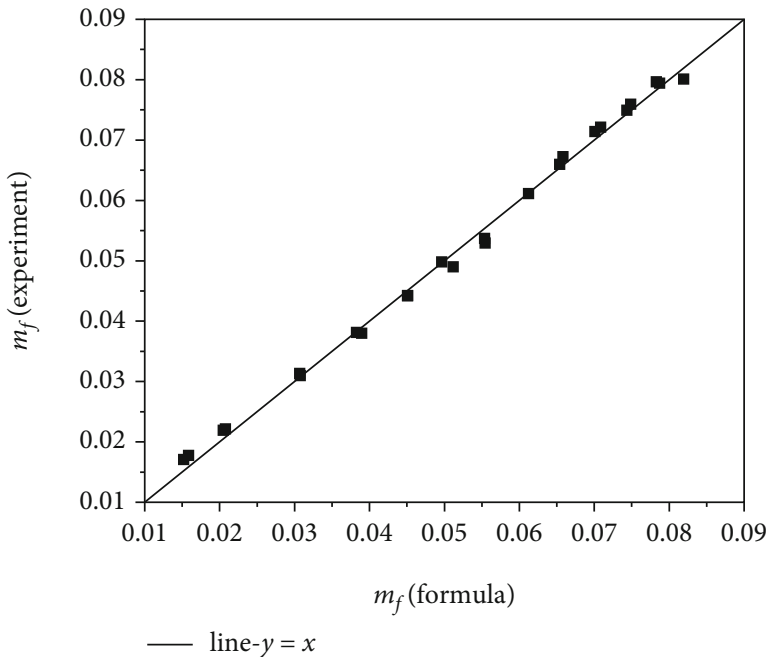

(a) Main fuel circuit

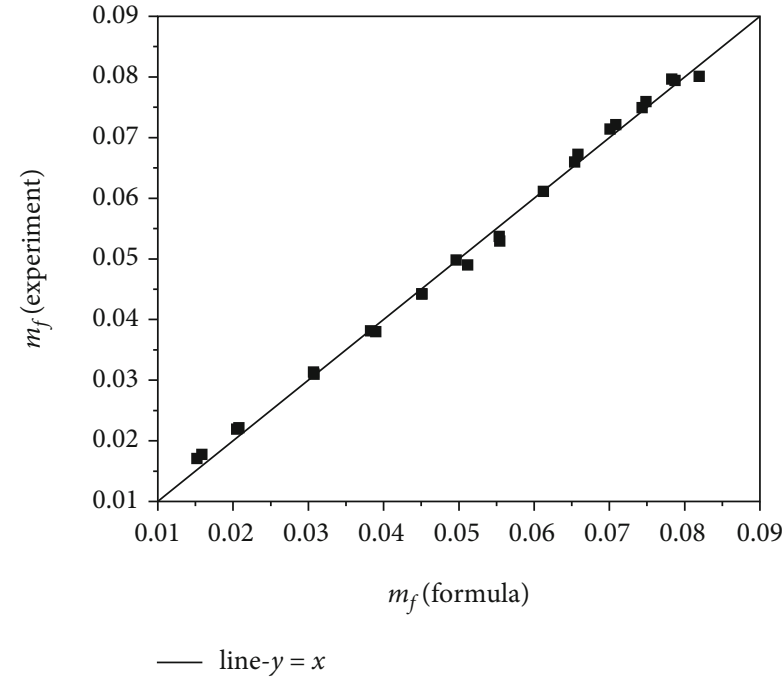

(b) Pilot fuel circuit

FIGURE 11: Relative error of empirical correlation.

in main fuel circuit and 7 times in the pilot. The results of calibrations has been shown in Figure 10. Here is the empirical correlations of fuel mass flux $m_{f}$ and fuel pressure differences $\Delta P_{\mathrm{f}}$, which is fitted by least square method application:

$$
\begin{aligned}
& \text { Main fuel path : } m_{f}=0.0308 \times \Delta P_{\mathrm{f}}^{0.554} \\
& \text { Pilot fuel path : } m_{f}=0.00546 \times \Delta P_{\mathrm{f}}^{0.486}
\end{aligned}
$$

where $m_{f}(\mathrm{~kg} / \mathrm{s})$ is the fuel mass flow rate and $\Delta P_{\mathrm{f}}$ is the fuel pressure differences between the injector inlet and outlet.

The comparisons of experimental parameters and fitting formulas are shown in Figure 11; the average errors of fitting formulas are lower than $1 \%$, which means the method of controlling mass flow rate and velocity by pressure is reliable.

\section{Data Analysis}

Fuel inlet velocity is calculated by calibrated mass flux and the fuel density:

$$
\mathrm{V}_{\mathrm{f}, \mathrm{i}}=\frac{\mathrm{m}_{\mathrm{f}}}{\rho_{f . i} \times A_{i}},
$$

where $V_{f i}$ is fuel inlet velocity, $\rho_{f . i}$ is fuel density, and $A_{i}$ is fuel path area.

Total pressure loss is defined as the total pressure difference of the first and the last measure point:

$$
\Delta P^{*}=P_{\mathrm{i}}^{*}-P_{\mathrm{o}}^{*},
$$

where $\Delta P^{*}$ is total pressure loss, $P^{*}{ }_{i}$ is inlet total pressure, and $P^{*}{ }_{o}$ is outlet environment pressure.
Total pressure loss coefficient is defined as

$$
\lambda=\frac{P_{\mathrm{i}}^{*}-P_{\mathrm{o}}^{*}}{P_{\mathrm{i}}^{*}},
$$

where $\lambda$ is total pressure loss coefficient, $P_{i}{ }^{*}$ is inlet total pressure, and $P^{*}{ }_{o}$ is outlet environment pressure.

Friction factor is defined as

$$
\xi=\frac{P_{i}^{*}-P_{\mathrm{o}}^{*}}{(1 / 2) \rho_{f . i} V_{\mathrm{f} . \mathrm{i}}^{2}},
$$

where $\xi$ is friction factor, $P_{i}{ }^{*}$ is inlet total pressure and $P^{s}{ }_{o}$ is outlet environment pressure, $\rho_{f . i}$ is fuel density, and $V_{f i}$ is fuel inlet velocity.

Table 3 gives the uncertainty of measured and derived quantities in the experiment.

\section{Results and Discussion}

\subsection{Results of Main Path}

5.1.1. Pressure Distribution. Figure 12 presents the pressure distribution of main fuel path with different fuel inlet temperature $T_{f . i}$ and inlet velocity $V_{f . i}$. As shown in the figure, the pressure gradually decreases along the main fuel path for each inlet temperature and inlet velocity. With the same temperature, the absolute values of pressure in the path significant increase with the inlet velocity. In fact, the maximum pressure loss present between measure points 1 and 2, where the radius of paths have changed.

5.1.2. Total Pressure Loss. The flow resistance losses include resistance loss along the path and local resistance loss. According to the boundary layer theory in turbulent pipe flow [17], with the increasing of velocity, the viscous sublayer become thinner which leads to the increases of frictional 


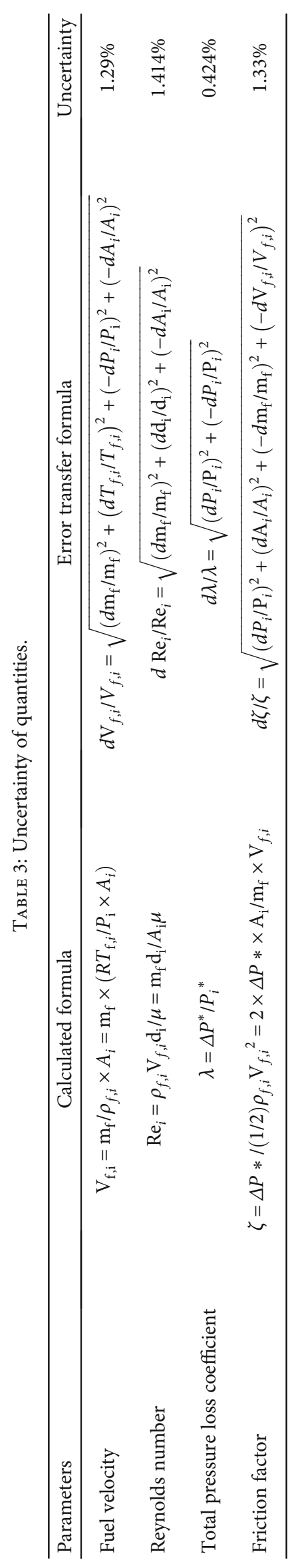




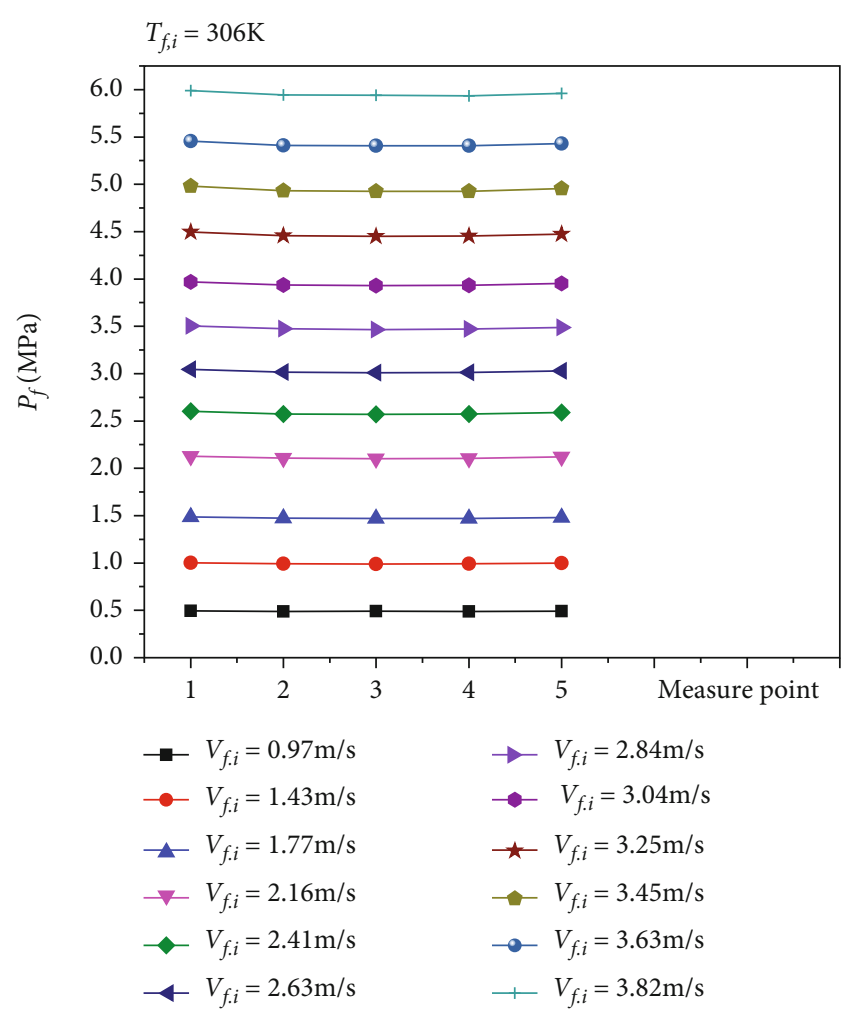

(a) $T_{f . i}=306 \mathrm{~K}$

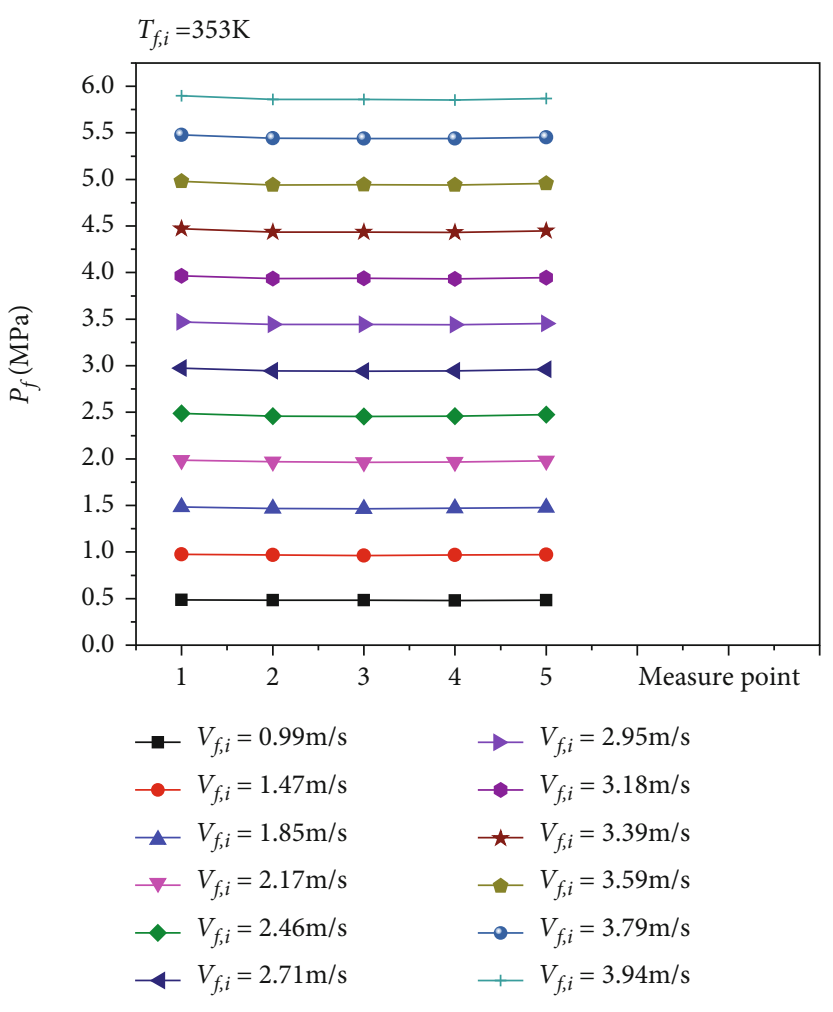

(b) $T_{f . i}=353 \mathrm{~K}$

FIGURE 12: Pressure distribution of main path.

resistance and the resistance along flow direction. Meanwhile, the structure of flow direction changing, variable cross section, and diffluence in the main path, which can result in the increase of local resistance losses, will lead the total pressure loss grow along the main fuel path. According to the empirical estimation, the resistance loss along the path accounts for almost $30 \%$ of the total pressure loss. The most important factor of pressure loss in the main path is the complicated structure of flow path. The variation of total pressure loss with fuel inlet velocity in different temperature was shown in Figure 13. It presents linear relation between the total pressure loss and inlet velocity square of main path with the same inlet temperature, which satisfy the general law even in the fuel jet circuit with complicated structure. While the effect of inlet temperature on the pressure loss is shown negligible for the same inlet velocity in the figure.

\subsubsection{Total Pressure Loss Coefficient and Friction Factor.}

From Figure 14 one can see the variation of total pressure loss coefficient with inlet Reynolds number in main fuel circuit. In general, the total pressure loss coefficient decreases slightly with the increase of Reynolds number at corresponding fuel temperature, and it stayed almost constant at 0.0055 for Reynolds number which is higher than 10000.

According to the classic Nicholas fluid experiments in rough pipe [18], for straight pipe whose relative roughness is $d / \Delta=0.001$, the friction factor tends to be independent of the Reynolds number when the inlet Reynolds number Re $>1 \times 10^{6}$ which means the flow is in the completely tur-

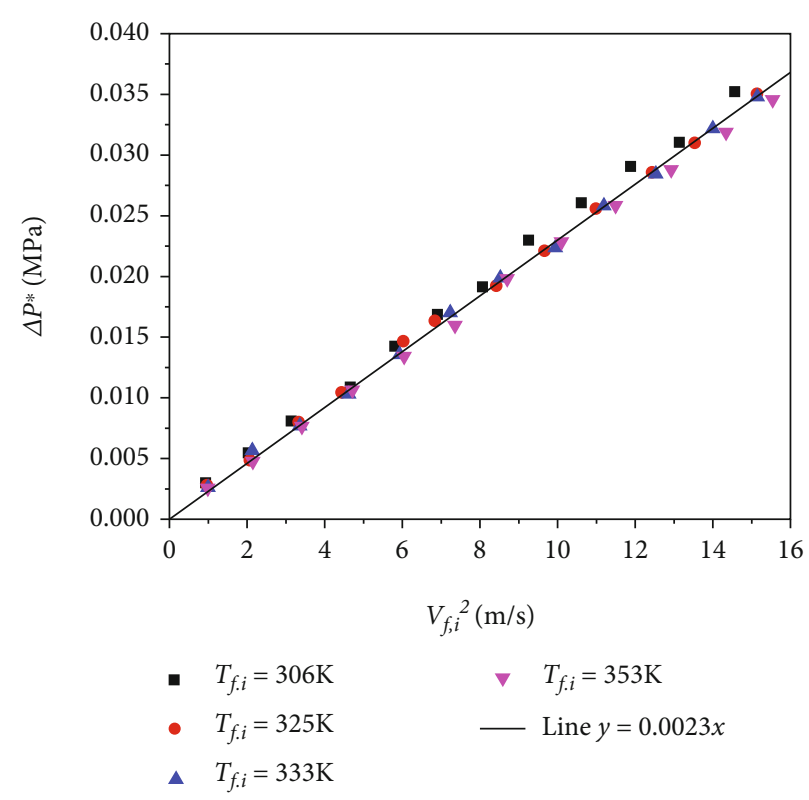

FIGURE 13: Total pressure loss variation with inlet velocity square in main fuel circuit.

bulent regime. As mentioned in some researches [19], the flow mixing will be strengthened and the flow will be more turbulent as the fluid flowing through the boundary with variable shape. Compared with relatively straight pipe, the flow in the complex structure will enter the completely turbulent 


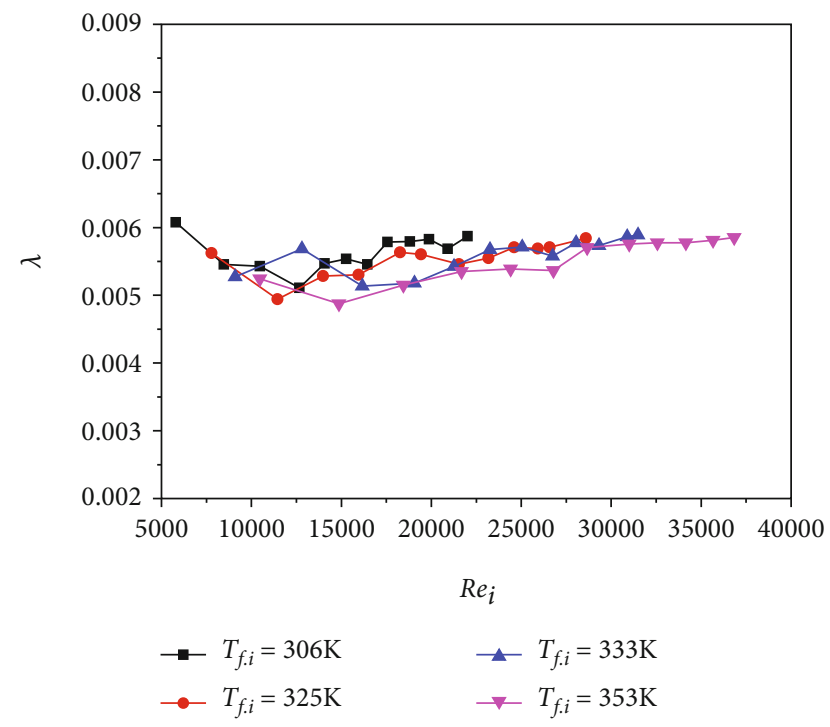

Figure 14: Variation of total pressure loss coefficient of main fuel circuit.

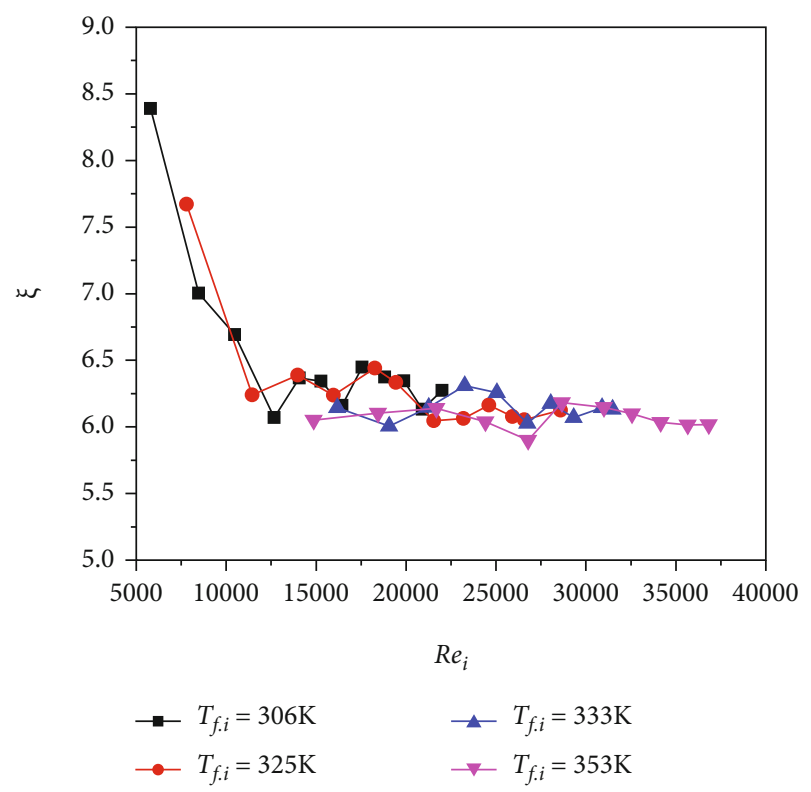

FIGURE 15: Variation of friction factor of main fuel path.

regime at a lower Reynolds number. For example, the pressure losses in closed-coupled fitting have been investigated in the paper [20]; it shows that the local friction factor is independent with Reynolds number for $\operatorname{Re}>1.5 \times 10^{5}$ in the test pipe. For the test nozzle with complicated structure of main path, the change curve of friction factor is shown in Figure 15; the friction factor of main fuel path decreases with the developed Reynolds number which is lower than $12000\left(\mathrm{Re}_{i} \leq 12000\right)$. Then, the friction factor tends to be constant at 6.1 as Reynolds number higher than $12000\left(\operatorname{Re}_{i}>12000\right)$, and the main fuel flow inside this structure is in completely turbulent regime. In addition, both total pressure loss coefficient and friction factor of main fuel path decrease slightly with the increase of inlet fuel temperature.

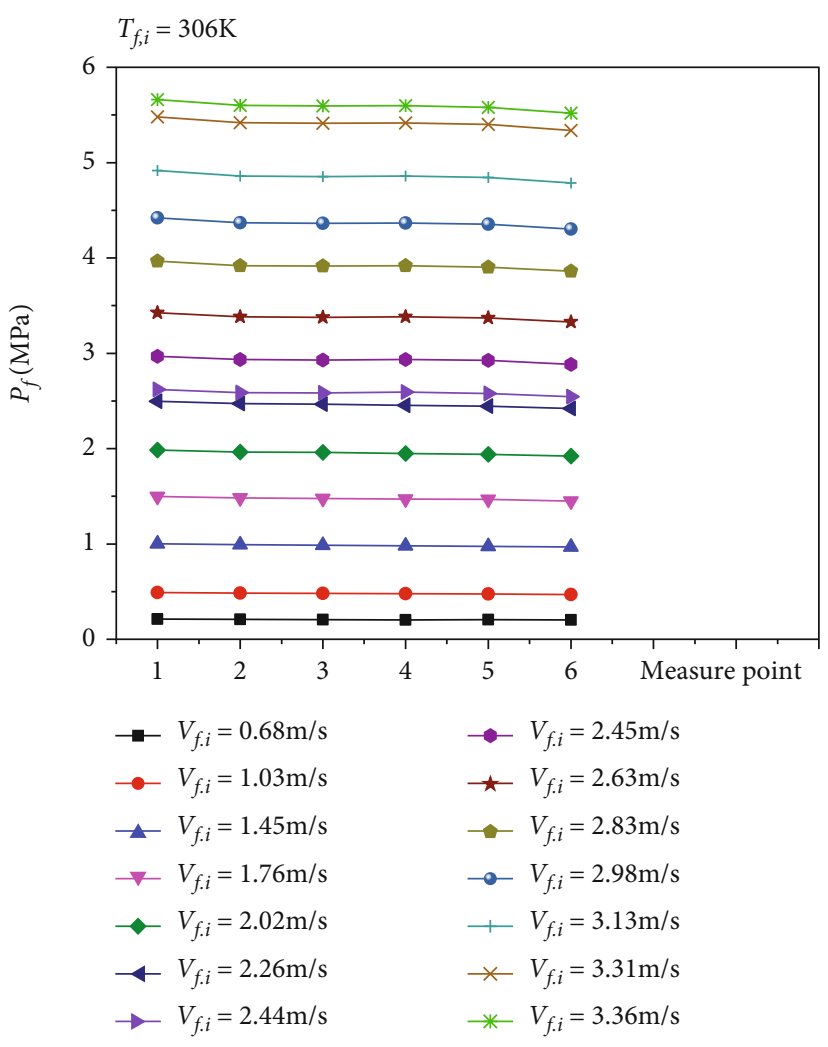

(a) $T_{f . i}=306 \mathrm{~K}$

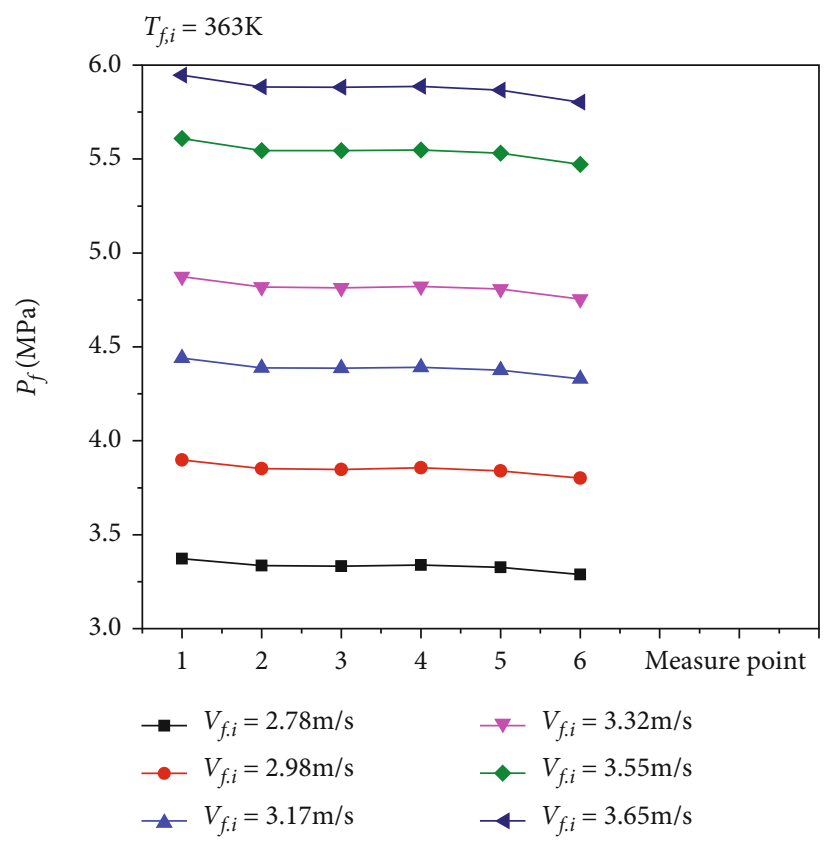

(b) $T_{f . i}=363 \mathrm{~K}$

FIgURe 16: Pressure distribution of pilot path.

\subsection{Results of Pilot Path}

5.2.1. Pressure Distribution. Figure 16 shows the pressure distribution of pilot fuel path in different fuel inlet temperature $T_{f . i}$ and inlet velocity $V_{f . i}$, which is similar to the main fuel path. As a result, pressure along pilot path progressively 


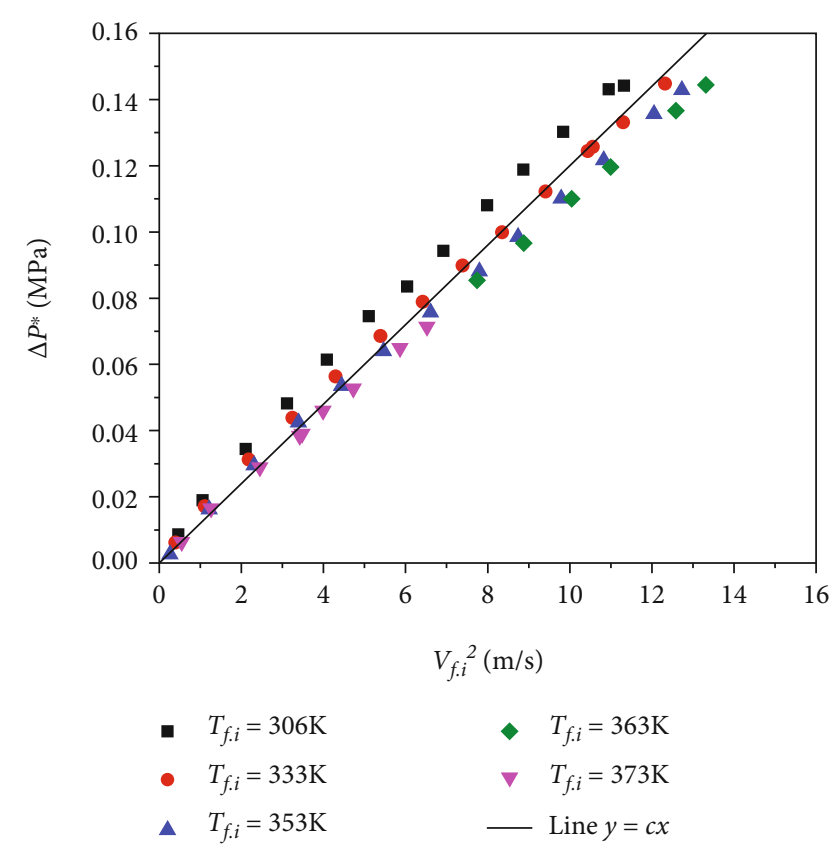

FIGURE 17: Total pressure loss variation with inlet velocity square in pilot fuel circuit.

decreases at the same condition. Furthermore, absolute value of pressure significantly elevate with the increase of inlet velocity. The highest pressure loss appears at the divided flow region and convergent flow region.

5.2.2. Total Pressure Loss. The variation of total pressure in main and pilot path are similar (Figure 17). For certain temperature, the total pressure loss grows with the inlet velocity. Compared with main path, the structure of pilot fuel path is more complicated, and there are more flow direction changing in pilot circuit of which the local pressure loss is bigger; at the same inlet velocity, their total pressure loss is almost 5 to 6 times larger than the main path. According to the empirical estimation, the local pressure loss accounts for almost $80 \%$ of the total pressure loss in pilot fuel circuit.

From Figure 17, the total pressure loss and inlet velocity square present linear relation. Compared with the main fuel path, the influence of temperature on total pressure loss is enhanced at the same inlet velocity. Higher temperature will change fuel properties and reduce the fuel viscosity, so that the slope of total pressure loss with the square of inlet flow rate is slightly reduced. However, the overall tendency of pressure loss in pilot path still satisfies the general law under the experimental conditions.

\subsubsection{Total Pressure Loss Coefficient and Friction Factor. In} Figure 18, the variation of total pressure loss coefficient at different temperature is ploted versus the inlet Reynolds number. Total pressure loss coefficient strongly decreases with the Reynolds number which is lower than 10000 $\left(\operatorname{Re}_{i}<10000\right)$. For Reynolds number $\operatorname{Re}_{i}>10000$, the total pressure loss coefficient tends to be a constant at 0.025 .

Figure 19 shows that the friction factor varies with the inlet Reynolds number; for inlet Reynolds number $\mathrm{Re}_{i}<10000$, the

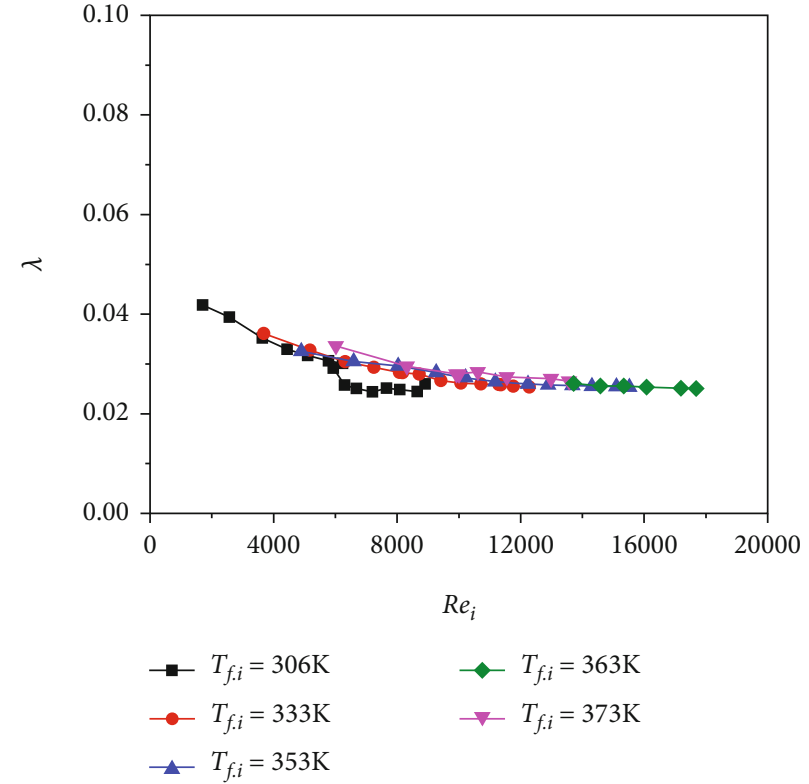

FIgURE 18: Variation of total pressure loss coefficient of pilot fuel circuit.

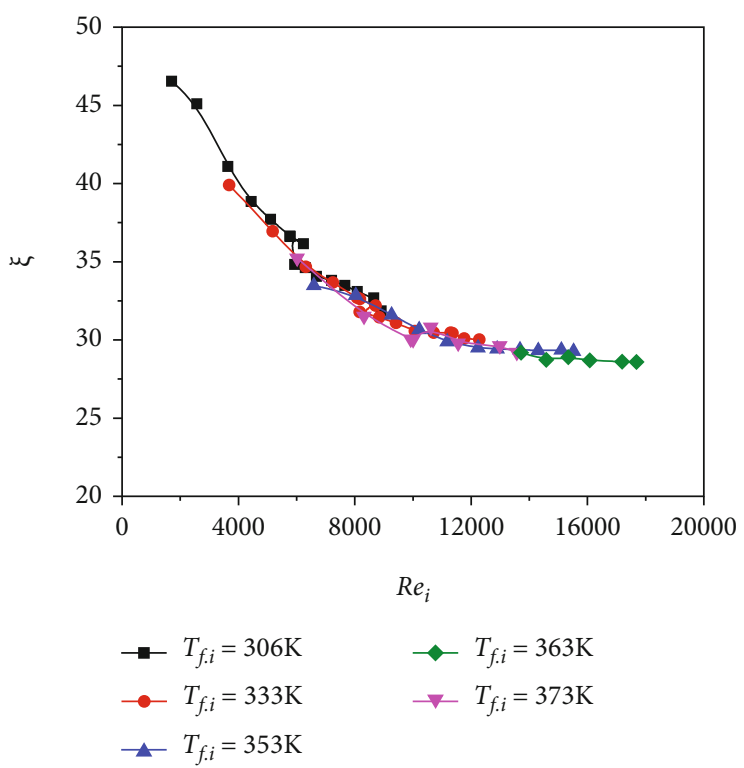

FIGURE 19: Variation of friction factor of main fuel path.

friction factor strongly decreases as Reynolds number increases. Then, after the Reynolds number increasing higher than 10000 , the friction factor reduces slightly and stays a constant value, which means the flow is in completely turbulent regime. Both total pressure loss coefficient and friction factors of pilot path are larger than those in the main path, because the more complicated circuit structure of pilot greatly increases the local resistance loss. For different fuel inlet temperature, both total pressure loss coefficient and friction factors in pilot path are close to unchanged under the same Reynolds number.

5.3. Empirical Correlation. In the present investigation, in regard to investigated injector structure, the empirical 


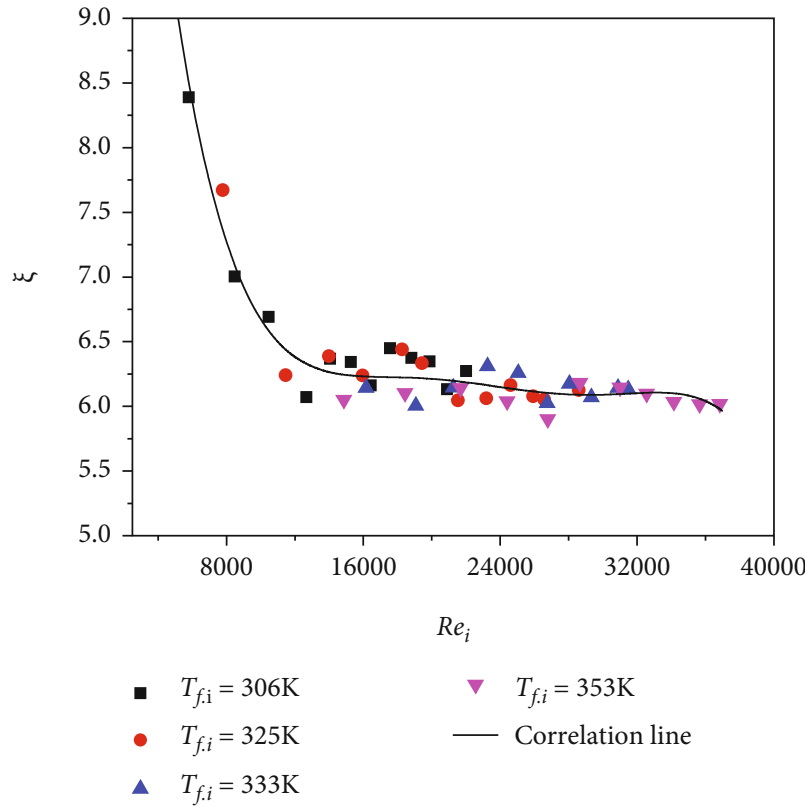

(a) Main fuel circuit

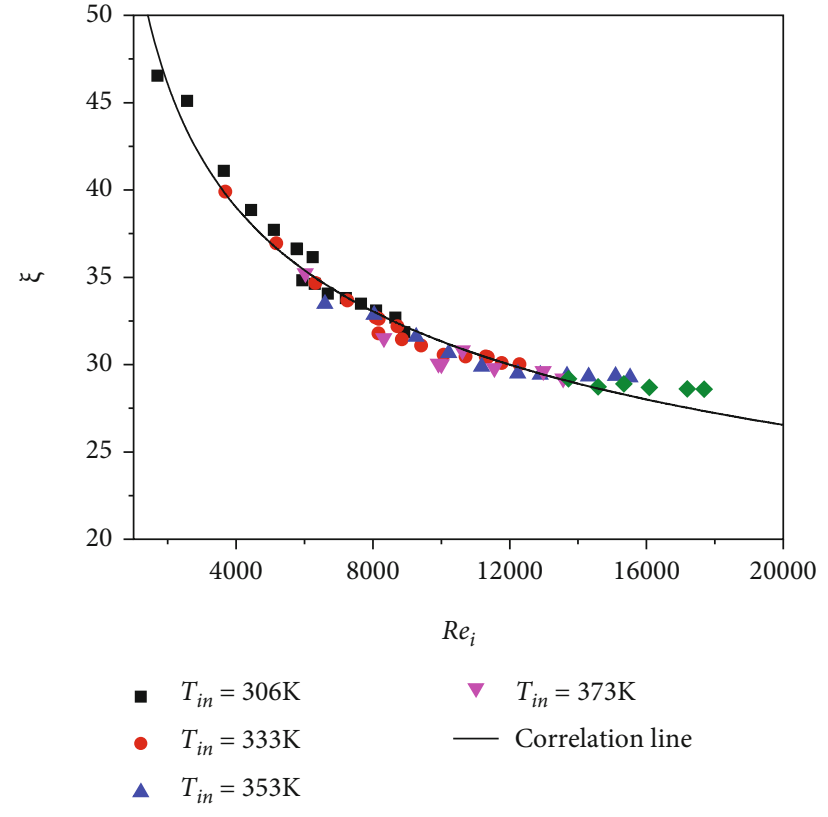

(b) Pilot fuel circuit

FIGURE 20: Comparison of correlation and measured data.

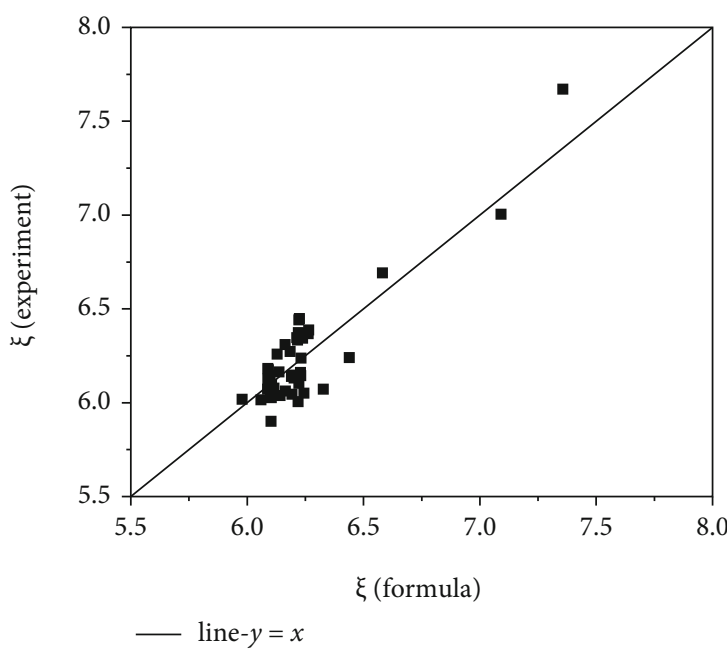

(a) Main fuel circuit

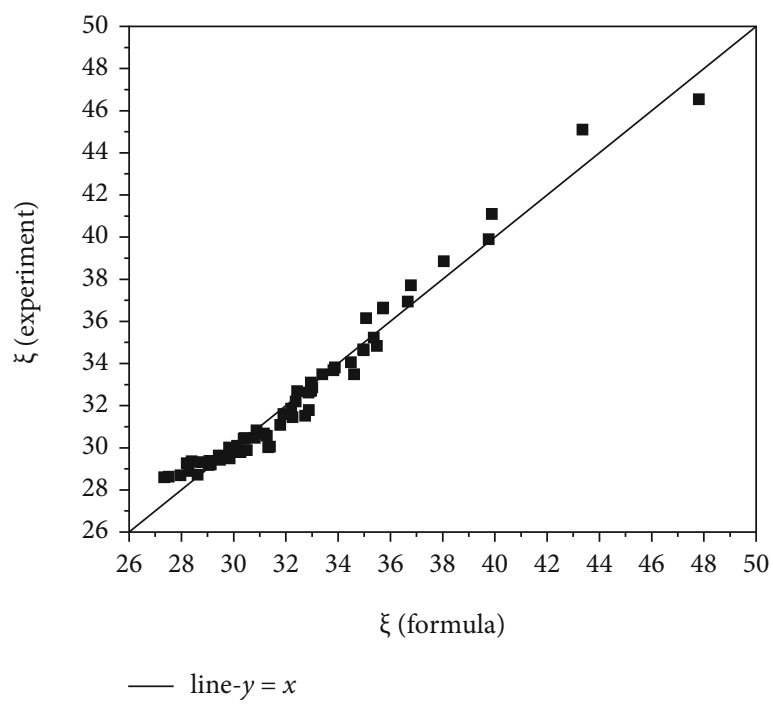

(b) Pilot fuel circuit

FIgURe 21: Relative error of empirical correlation.

correlations of total pressure loss fraction versus Reynolds number for the main and pilot fuel path friction factor for different Reynolds number have been developed by using least square method. The functional relation between main path friction factor and inlet Reynolds number is derived from polynomial, that is,

$$
\begin{aligned}
& \xi= 17.13-0.002 \times \operatorname{Re}_{f . \mathrm{i}}+2.3 \times 10^{-7} \times \mathrm{Re}_{f . i}^{2}-9.8 \times 10^{-12} \\
& \times \operatorname{Re}_{f . i}^{3}+2 \times 10^{-16} \times \operatorname{Re}_{f . i}^{4}+1.7 \times 10^{-21} \times \operatorname{Re}_{f . i}^{5},
\end{aligned}
$$

The comparison of measured data with the correlation is given in Figure 20(a), the value of average data errors is lower than 5\%, and Figure 21(a) described clearly the relative error of correlation.

Here is the empirical correlation between friction factor and Reynolds number of pilot fuel path, which is in exponential distribution.

$$
\xi=283.123 \times \operatorname{Re}_{i}^{-0.239}
$$

where $\xi$ is friction factor and $\mathrm{Re}_{i}$ is inlet Reynolds number. 
As result of correlation shown in Figure 20(b) and Figure 21(b), the value of average data errors for pilot fuel path is lower than $5 \%$.

\section{Conclusions}

In this paper, based on a typical triple-stage rotating swirling, the experiment on the resistance characteristics for main and pilot path flow has been implemented. This work studied the effect of different inlet velocity and temperature for investigated fuel circuit system. In addition, the empirical correlations between friction factor and inlet Reynolds number are obtained and good agreement was observed. Major findings are as follows:

(1) The local resistance loss dominates in both main fuel path and pilot fuel path. Due to complex configuration of pilot fuel circuit, the pilot oil-cooling structure design will strongly increase the local resistance loss. Their flow resistance loss is more than 4 times higher than that in the main fuel path at the same Reynolds number. Hence, the major point during the nozzle structure designing is decreasing the local resistance loss, and the total pressure loss of whole oil circuit will be decreased

(2) For main fuel circuit, the highest pressure loss occurred at the divided flow region; for pilot fuel circuit, the highest pressure loss appeared at the divided flow region and the convergent flow region

(3) Under the investigated conditions of present studies, the inlet temperature has slight influence on total pressure loss at different velocity. Both in main and pilot fuel circuit, the total pressure loss presents exponential growth with the inlet velocity and linear growth with the square of inlet velocity

(4) Both total pressure loss coefficient and friction factor reduce as the inlet Reynolds number rises. For main fuel path, the total pressure loss coefficient stayed almost constant at 0.0055 for Reynolds number which is higher than 10000, and the friction factor tends to be constant at 6.1 as Reynolds number is higher than 12000. For pilot fuel path, the total pressure loss stayed around 0.025 , and the friction factor is almost 29 as Reynolds number is higher than 10000

\section{Nomenclature}

IHPTET: The Integrated High Performance Turbine Technology Program

ECCP: Experimental Clean Combustor Program

PRTP: $\quad$ Pollution Reduction Technology Program

TAPS: $\quad$ Twin Annular Premixing Swirler

GE: $\quad$ General Electric

$\rho: \quad$ Density of fuel $\left(\mathrm{kg} / \mathrm{m}^{3}\right)$

$\mu: \quad$ Viscosity coefficient $\left(\mathrm{m}^{2} / \mathrm{s}\right)$

$m_{f}: \quad$ Mass flow of fuel $(\mathrm{kg} / \mathrm{s})$

$\Delta P_{\mathrm{f}}: \quad$ Pressure difference of fuel supply $(\mathrm{MPa})$
$P_{\mathrm{i}}: \quad \quad \quad \quad$ Pressure of measuring point $i(\mathrm{MPa})$

$V_{f i}: \quad$ Inlet velosity of fuel $(\mathrm{m} / \mathrm{s})$

$P_{\mathrm{i}}^{*}: \quad$ Total pressure of measuring point $i(\mathrm{MPa})$

$\Delta P^{*}: \quad$ Total pressure loss $(\mathrm{MPa})$

$\lambda: \quad$ Total pressure loss coefficient

$\xi: \quad$ Friction factor

Re: $\quad$ Reynolds number

$T_{f, i}: \quad$ Inlet temperature of fuel $(\mathrm{K})$.

\section{Data Availability}

All data generated or analyzed during this study are included in this article.

\section{Conflicts of Interest}

We declare that we have no financial and personal relationships with other people or organizations that can inappropriately influence our work; there is no professional or other personal interest of any nature or kind in any product, service, and/or company that could be construed as influencing the position presented in, or the review of, the manuscript entitled.

\section{Acknowledgments}

This work was supported by the National Science and Technology Major Project (2017-Ill-0008-0034).

\section{References}

[1] B. Croswell and T. Biddle, "High temperature fuel requirements and payoffs," in Aviation Fuel: Thermal Stability Requirements, pp. 57-72, PA: ASTM International, West Conshohocken, 1992.

[2] P. VIARS, "The impact of IHPTET on the engine/aircraft system," in Aircraft Design and Operations Meeting, Seattle,WA,U.S.A., 1989.

[3] T. Edwards, W. Harrison, S. Zabarnick, M. DeWitt, and C. Bentz, "Update on the development of JP-8+100," in 40th AIAA/ASME/SAE/ASEE Joint Propulsion Conference and Exhibit, pp. 1-14, Fort Lauderdale, Florida, 2004.

[4] R. Hazlett, Ed., Thermal Oxidation Stability of Aviation Turbine Fuels, ASTM International, West Conshohocken, PA, 1991.

[5] H. C. Mongia and W. G. A. E. Dodds, "Low emissions propulsion engine combustor technology evolution past, present and future," in 24th Congress of International Council of the Aeronautical Sciences, Yokohama, Japan, 2004.

[6] H. C. Mongia, "TAPS-A 4th generation propulsion combustor technology for low emissions," in AIAA International Air and Space Symposium and Exposition: The Next 100 Years, Dayton, Ohio, 2003.

[7] M. J. Foust, D. Thomsen, R. Stickles, C. Cooper, and W. Dodds, "Development of the GE aviation low emissions TAPS combustor for next generation aircraft engines," in 50th AIAA Aerospace Sciences Meeting including the New Horizons Forum and Aerospace Exposition, pp. 1-9, Nashville, Tennessee, 2012. 
[8] H. C. Mongia, "Perspective of combustion modeling for gas turbine combustors," in 42nd AIAA Aerospace Sciences Meeting and Exhibit, pp. 1759-1791, Reno, Nevada, 2004.

[9] R. W. Stickles, W. J. Dodds, T. R. Koblish, J. Sager, and S. Clouser, "Innovative high temperature aircraft engine fuel nozzle design," in Volume 3: Coal, Biomass and Alternative Fuels; Combustion and Fuels; Oil and Gas Applications; Cycle Innovations, Cologne, Germany, 1992.

[10] G. E. Moertle and E. C. Vickers, Methods and apparatus for shielding heat from a fuel nozzle stem of fuel nozzle, United States General Electric Company, Cincinnati, OH, 2000, https://www.freepatentsonline.com/6149075.html.

[11] G. D. Myers, J. P. Armstrong, C. D. White, S. Clouser, and R. J. Harvey, "Development of an innovative high-temperature gas turbine fuel nozzle," in Volume 3: Coal, Biomass and Alternative Fuels; Combustion and Fuels; Oil and Gas Applications; Cycle Innovations, Orlando, Florida, USA, 1991.

[12] E. G. Jones and W. J. Balster, "Phenomenological study of the formation of insolubles in a Jet-A fuel," Energy \& Fuels, vol. 7, no. 6, pp. 968-977, 1993.

[13] A. A. Mancini and D. D. Thomsen, Differential Pressure Induced Purging Fuel Injector with Asymmetric Cyclone, United States General Electric Company, Schenectady, NY, US, 2005, https://www.freepatentsonline.com/6898938.html.

[14] D. R. Barnhart and J. T. Mook, Fuel Nozzle with Fluid Lock and Purge Apparatus, United States General Electric Company, Schenectady, NY, US, 2019, https://www.freepatentsonline .com/10288293.html.

[15] E. Daniau and M. Sicard, "Experimental and numerical investigations of an endothermic fuel cooling capacity for scramjet application," in AIAA/CIRA 13th International Space Planes and Hypersonics Systems and Technologies Conference, pp. 1808-1816, Capua, Italy, 2005.

[16] I. Idelchik, Flow resistance: a design guide for engineers, Routledge, New York, 2017.

[17] P. Kundu, I. Cohen, and D. Dowling, Fluid Mechanics, Academic Press, New York, 6 edition, 2016.

[18] J. Nikuradse, "National Advisory Committee for Aeronautics," Journal of Applied Physics, vol. 14, no. 8, pp. 399-405, 1943.

[19] Y.-y. He, Z. Yi-jun, S. Shu-qing, and M. Shi-min, "Experimental study on local loss coefficient of bend in pipeline," Journal of Hydraulic Engineering, vol. 34, pp. 54-58, 2003.

[20] S. Sami and J. Cui, "Numerical study of pressure losses in close-coupled fittings," HVAC \& R Research, vol. 10, no. 4, pp. 539-552, 2004. 